\title{
Examining Instructor's and Student's Perceptions in an after School Program Focused on Emotional Recovery following a Natural Disaster
}

\author{
By Zachary Wahl-Alexander* \\ Oleg A. Sinelnikov ${ }^{\dagger}$
}

This study examined students and instructors perceptions of their participation in a physical activity after school program focused on emotional recovery following a natural disaster. Forty-five elementary aged children and four instructors participated in the study. Student and instructor perceptions were observed through non-participant observation, formal and informal interviews. Results showed that the children expressed enjoyment of the physical education portion of the program, while communicating that the stress reducing techniques were applicable, practical, simple to use, multi-dimensional and transferable to other contexts. The instructors expressed both apprehension and excitement about initiating the program, while voicing guilt and a desire to give back to the community for reasons to participate.

Keywords: Emotional Recovery, Physical Education, Stress Reducing Techniques, Teaching.

\section{Introduction}

Children who are either directly or indirectly affected by a natural disaster often exhibit numerous emotional reactions. Shock and denial are two specific responses by children, which generally follow a traumatic experience. After the initial shock from the disaster dissipates, a number of responses regularly transpire including disbelief, fear, sadness, helplessness and guilt (Myers 1994). While only as small portion of children (5-10\%) exposed to natural disasters develop post traumatic stress disorder (PTSD), a majority of children display high levels of stress symptoms a year following such events (Vogel and Vernberg 1993, La Greca and Prinstein 2002, Lonigan et al. 2003).

Even though children may not develop PTSD symptoms, this does not mean they are not affected. Additional symptoms succeeding natural disasters include fear, depression, self-blame, guilt, loss of interest in school and athletics, regressive behavior, sleep disturbances, poor concentration and separation anxiety (Speier 2000). It is normal for children to externalize

\footnotetext{
* Assistant Professor, Northern Illinois University, USA.

${ }^{\dagger}$ Associate Professor, University of Alabama, USA.
} 
these emotions and act more aggressive or displace these emotions onto others (Webb 2004). Becker-Blease et al. (2010) established that children who experience such traumatic event during their lifetimes are at a heightened risk for an assortment of negative psychological problems, including depression, anxiety and anger or aggression. During and immediately ensuing these instances, children are particularly susceptible to these symptoms due to the fact that they have not yet fully developed sufficient coping skills (Perry et al. 1995). Although a majority of children display these typical signs; research suggests that a high likelihood of symptoms dissipate when parents or teachers introduce specific coping strategies (Speier 2000).

Teachers can become skillful in reducing these effects due to their central role in children's lives. Children who received teacher directed interventions have shown higher recovery rates than youth not receiving this same teacher directed intervention (Wolmer et al. 2005). Normally, parents and teachers do not have the appropriate knowledge or training to carry out intervention programs, nevertheless family therapists can take full advantage of their efforts by providing simplistic training to parents and teachers to aid in providing basic interventions for children (Harper et al. 2003).

There are a variety of techniques teachers and parents can promote without receiving any professional training. Following Hurricane Katrina in Louisiana, Carson (2008) implemented a service-learning program that provided organized physical activity to children displaced after Hurricane Katrina. The programs goals were to provide safe activity programming to school aged children, while developing a sense of community among the displaced children through cooperative challenges and group building exercises. This program was found to be effective in promoting lifelong fitness, while providing fun activities to distract the children from the surrounding turmoil.

Researchers have recommended physical activity as an effective approach for reducing stress in children who are dealing with the effects of a natural disaster (Dunn et al. 2001). There are a variety of positive cognitive, emotional, physiological and behavioral coping strategies for children, which can be assimilated within the physical activity setting for a more profound impact (Baggerly and Exum 2008).

Self-talk is defined as statements said to oneself with the goal of reducing anxiety and stress (Hardy 2006). These statements can be said either aloud or mentally and have been described "as a small voice in their own head" (Theodorakis et al. 2000). While self-talk can be positive, negative or neutral, positive self-talk seems to be the most beneficial. Researchers have shown it can enhance and improve self-esteem and motivation or help concentration on a current task (Weinberg 1988). Positive self-talk has also been determined to aid in increasing the acquisition of skills, the development of self-confidence and the selfregulation of habits (Weinberg et al. 1992). 
Deep breathing is another primary physiological stress reducing technique used by both children and adults in arduous situations (Lehrer et al. 2007). It has been used to combat a variety of diseases such as hypertension, pulmonary diseases, depression and stress related disorders (Han et al. 1996). Because deep breathing techniques can have such a significant effect on the improvement of tension following acute stressful tasks, this technique has been shown to diminish male adolescent aggressive behavior. In an article outlining the guidelines of American Red Cross and Psychological First Aid, Warchal and Graham (2011) described teaching survivors of natural disasters self-soothing techniques such as relaxation and deep breathing to aid in the recovery process.

Art therapy is a mental health tool incorporating the process of creating artwork to explore feelings, emotional conflicts, reduce anxiety and increase self-esteem (Eaton et al. 2007). Unlike other psychological therapies art therapy does not exclusively utilize verbal communication (Stevenson and Orr 2013), which is extremely beneficial when attempting to communicate with younger children who struggle to express themselves. Another benefit of art therapy is that no previous experience is required and is a simplistic way to express feelings of anxiety, guilt, depression or grief (Shore 1997).

Art therapy has been proven to improve the emotional functioning in children who are suffering from high levels of stress following a traumatic event (Carolan 2001, Deaver 2002, Slayton et al. 2010). After such events young children may not be able or willing to verbalize feelings, so offering other communicative modes can be more effective (Webb 2004). By merging the senses through observation, touching or manipulating art materials, children can positively reinterpret their perceptions of traumatic events (Appleton 2001, Sarid and Huss 2010).

Previous research has identified many effective methods of reducing anxiety levels in children following a traumatic event. This study examined what children and instructors thought about their participation within an after school program aimed at integrating these techniques within developmentally appropriate physical activity. The research question was not directed at the effectiveness of the methods since research has proved these methods to be quite successful, but focused on student experiences participating in the program and the instructor's perceptions of delivering such a program. The purpose of this study was to evaluate students and instructors perceptions of their participation in a physical activity after school program.

\section{Methods}

\section{Participants and Setting}

Student participants were forty-five elementary aged children (average age 8.4) enrolled in an after school program at a public, southern, rural 
elementary school. Permission to conduct the study was obtained before the investigation from the universities review board, the school district, the participants and their parents.

The four lead instructors who facilitated the program all signed consent forms and were cognizant of the study procedures. The instructors were all Graduate Teaching Assistants (GTAs) in the Kinesiology department at a major research university in the southeastern part of the United States. Each instructor (average age 23.1) had a minimum of three years teaching experience in physical education prior to this program. Three of the GTAs were enrolled in masters degree coursework, with one was completing their $\mathrm{PhD}$ in Human Performance. All four instructors were directly affected by the natural disaster that devastated the local area and was the motivation behind the program. Instructor level of affectedness ranged from losing their apartment, belongings and automobiles, to being trapped in their basement while awaiting assistance on the day of the storm.

\section{Program Description}

The emotional recovery program included somatic, psychological stress reducing, art therapy sessions and group sharing sessions, all of which were integrated with a developmentally appropriate physical activity setting (Wahl-Alexander and Sinelnikov 2013). Each of the somatic (positive selftalk) and psychological (deep breathing and muscle relaxation) components were infused throughout each session within bouts of physical activity. In contrast, the group sharing and art therapy occurred during allocated time between twenty-minute sessions of physical activity. For a thorough description of the contents of each session see Wahl-Alexander \& Sinelnikov (2013). Each session lasted sixty minutes, containing an initial period of physical activity, a group or art therapy twenty-minute recovery session and concluded with twenty additional minutes of physical activity.

\section{Data Collection}

Four qualitative techniques were used to collect data which aided in examining and describing the teachers experiences in an after school program focused on emotional recovery from a natural disaster. Nonparticipant observation involved observing the four teachers' instruction and taking extensive field notes during all 16 instructional sessions. All four instructors were formally interviewed twice. The first interview occurred before the program commenced. The purpose of these interviews was to obtain background information and a description of expectations. Additionally, the teachers were asked about their experiences during the storms on 27 April 2012. The second interview was conducted at the conclusion of the sessions with a focus on the program. The research question served as the foundation for the latter interview with a semistructured protocol (Patton 1990) allowing for multiple follow-up prompts 
and questions. Both formal interviews lasted approximately 45 minutes and were audio taped and transcribed verbatim.

Furthermore, as the opportunity presented itself, the teachers were informally interviewed. As informal interviews occurred, notes were made immediately after the interview. The teachers were asked to submit two focused critical incident reflections (Flanagan 1954) following each session. Within each reflection, the teachers responded to the questions: "what was the most meaningful experience for you today?", and "what was the most meaningful experience for your students today?"

In addition, two qualitative methods were collected to examine and describing the children's involvement in an after school program. Nonparticipant observation involved observing each child actively participating in every aspect of each lesson and taking extensive field notes. Finally, twenty-six of the children who participated were formally interviewed at the onset and conclusion of the program. These interviews lasted approximately fifteen minutes, with the goal of obtaining information pertaining to the research question.

\section{Data Analysis}

The initial phase of the data analysis involved creating codes and categories using analytic induction and constant comparison (Goetz and LeCompte 1984). Once categories were determined, common themes were created using data from all sources and both participants, the instructors and students. Trustworthiness and credibility was utilized by incorporating triangulation of the data from multiple sources, member checking and identifying negative or discrepant cases (Goetz and LeCompte 1984).

\section{Results}

\section{Children's Perceptions of the Program}

All children who participated in the recovery program repeatedly expressed their enjoyment of every aspect of the program. Not only did they "have fun each time we came to soccer", but acknowledged "learning something new every time I came":

I like knowing that I have the soccer program each Tuesday and Thursday, because I always go home from it happier than when I came. There is never a time that I am not smiling and having fun, but I learn a lot too. My coaches are also so nice. (Olivia formal interview).

Man, you know I like coming here each week. I love being able to show off my soccer skills and it always feels nice to see you guys 
(instructors). I look forward to every session because I have so much fun. (Steven formal interview).

They clearly perceive the program as enjoyable, while still appreciating the other aspects as well. "I really enjoyed learning the stress reducing techniques during the program. I use the positive self-talk and deep breathing almost every day":

One of the best parts of the soccer program was learning what to do when I get upset or angry or stressed. I used to get upset all the time, but now when I feel like this, I know there are different thing I can do that will make me feel better. (Josh formal interview).

Although some of these stress-reducing techniques were advanced, the majority of the children recognized the benefit of these methods and could clearly describe them. These students believed that the program was beneficial by not only providing them with a positive environment where they could have fun but recognized the benefits of learning how to cope with stress.

\section{Enjoyment of physical education}

Physical activity has been shown as beneficial for reducing anxiety, decreasing symptoms of depression, while improving self-esteem and mood (Biddle and Asare 2011). During the program, students consistently described high levels of enjoyment of participating in soccer. They described this aspect of the program as "so much fun, one of the best parts" and "I always want to keep playing. I play this a lot home to cause its so much fun":

One of my favorite parts of this program was when we play soccer. All the teachers are so nice, they taught me a lot and another thing is that it is just so fun. And I have not had a lot of fun like this in a long time. (Amelia formal interview).

I really liked playing soccer with all my classmates. I liked it even more after a long day or a test. I love to come out and play it always helps me feel better after a long, exhausting, stressful day in school. It always helped me to relax. (Josh formal interview).

The children frequently explained the positive impact of physical activity on the program. When asked to describe their favorite aspects of the program, students responded by declaring that they "Loved playing soccer and doing all the other stuff outside". Not only was it pleasurable, but as Josh described above, it helped relieve stress which had been built up in a majority of the students for some time. 
Additionally, there was a positive reaction from the lower skilled females who attended the program. These females agreed that they "Love to just play soccer, but the instructors helped me find that out because I never knew that I could actually play before".

I did not know how to kick a soccer ball at all before the program started and now I can kick one really far and directly at someone if I want to. I really never had the chance to play many sports before and I did not know that I liked them until now. I loved going home and telling my parents how much better I have gotten at soccer. (Elizabeth formal interview).

Not only did the high skilled males who traditionally excel in physical education (PE) appreciate the activities, the lower skilled females remarked of their high level of enjoyment for it as well. These students explain that they "enjoy the soccer portion, because they learn things they never learned before". The students professed that the opportunity for physical activity and the positive learning environment was "a great fun, but also really helped me feel better about myself more and more each time I came".

\section{Applicability and practicality}

At the onset of the program, when asked if they would do anything different if another storm approached children communicated a variety of techniques:

I would take the deep breathing, I use it a lot since y'all taught it to me and it helps me a lot too. If another bad storm were to come, I would probably just sit in my bathroom and calm myself down by breathing slow. If there was a storm coming I would probably use it then. (Amelia formal interview).

If there was another bad storm I would probably use the deep breathing and the self-talk because I mean, it is either going to be good or bad so you might as well hope that it is going to end up good. I would just keep telling myself that everything will turn out ok. (Josh formal interview).

I lost my house in the first tornado and I was really very scared during that. This time I would still be scared, because my house just got rebuilt and I do not want to lose it again. I think this time I would sit in my closet with my parents and tell myself that everything would be ok. I learned here at Soccer that sometimes when I draw it makes me feel better if I do all that stuff everything will work out ok. (Trinity formal interview).

These students demonstrate their ability to apply the deep breathing, positive self-talk and also drawing at the onset of another traumatic event. 
All of the children expressed their beliefs that using the new tactics they learned during this program would reduce the stress they would feel during another traumatic experience. The instructors of the program reiterate this sentiment by agreeing that the children understood the benefits to using these techniques if faced with another distressing situation:

When I would ask them afterwards what they would do in this type situation or if a tornado came again or stressed and I do not know and the fact that they were so young I think that it really did stick to them. I do not think they were the type of people that were just telling me what I wanted to hear. They would tell me if they got stressed or if another tornado were to come. They would do the PST to make them feel better. (Wendy stimulated recall interview).

By introducing and providing a variety of methods of stress reducing techniques in a simple manner, the children were able to apply what they have learned to real life situations. Not only did these children use the techniques repeatedly during the program, but they explained that if another storm were to occur they understood the tools they learned would work and those they were going to use them.

\section{Simplicity}

In order for children to gain the maximum benefit from a stress reduction method, it is imperative that the technique is simple and easy to recall (Vogel and Vernberg 1993). These children expressed the effortless nature of the techniques learned throughout the program. Kindergarten students were able to implement and express the deep breathing strategy proving its effectiveness and simplicity. "I like to deep breath the best. It makes me feel good and it is so easy to do". Olivia, a $3^{\text {rd }}$ grade expressed the straightforwardness of using the deep breathing at home and at school:

I like to use the deep breathing the best, because it is just very easy. Sometimes at home I lie down and use it. Sometimes I just sit at my desk, close my eyes and breathe slowly. It makes me feel better. (Olivia formal interview).

I use the deep breathing every morning when I wake up, because it is just so easy to use. I wake up, I am in my bed and I am so grouchy and really tired and I do not want to get up, so I do my deep breathing and that helps me want to get up and start the day. (Trinity formal interview).

Others described their belief that positive self-talk was both beneficial and easy to implement. "I like using the positive self-talk, it is really easy and so helpful". 
Sometimes, when I get frustrated or upset at something, I will just tell myself that everything will be ok. Everything will be ok. I will repeat something easy like that and it calms me down so much. (Trinity formal interview).

Although the majority of students found the deep breathing easier to grasp then the positive self-talk the children expressed both techniques as "easy and helpful".

Multi-Dimensionality

The instructors described, "Children telling them they could use these techniques in any stressful situation at home or school, anywhere they felt they were stressed or could not control what was going on". This showed the children's ability to demonstrate a high level of understanding for these stress reduction techniques as they explain their ability to use them in other facets of their life:

The younger students seemed to really use Positive self-talk all the time. We told them that if they get worried or upset, think in their head that everything is going to turn out alright or that they can do it. We told them that it was important to use the positive self-talk at school if they had a hard math problem or something, they could say that it was going to be ok if they cannot do it. It is fine not to be able to do something. Same thing with sports activities, they can use the self-talk in any kind of stressful situation. Just tell yourself that everything is going to be ok. (Tonya formal interview).

The deep breathing and positive self-talk were incorporated into students' daily lives in many settings, showing that the techniques had a multi-dimensionality of use. Many children described the helpfulness of deep breathing and positive-self talk prior to taking tests. "I like to use the deep breathing right before I take a test or any other times at school when I am nervous".

Sometimes I will use the positive self-talk when I am taking tests at school or when I am trying to learn how to do something that is frustrating. If I cannot do something or if I am having trouble doing something I will say, I think I can, I think I can. (Amelia formal interview).

Once, I had this really important science project at the science fair. I did the self-talk a lot that day because it was very stressful and I think I did some deep breathing their too. (Josh, formal interview).

Becca, the instructor of the $3^{\text {rd }}-5^{\text {th }}$ graders explained "They would all talk about using the techniques at school before a test or big assignment. 
They all told me they use it at school". Not only were these methods depicted in the school setting, others described using the stress reducing techniques during sports or when parents fight:

I like the positive self-talk because I play a lot of sports where sometimes you have really good moments and sometimes you do not. When you play tennis when you have a bad shot you just have to forget about it. It really helps knowing all the things you can say especially after a bad shot. I will say it is just one shot; it is going to be fine. (Josh formal interview).

I play basketball a lot or soccer a lot and sometimes I do not play so good and I will tell myself that I am better than this. That it is just one bad day that I will play better the next time. It always makes me feel good knowing that. (Kendall formal interview).

I have used a lot of the stress reducing techniques. Sometimes at home I use the deep breathing when my parents are fighting. I like to focus on my breathing, not them yelling. (Amelia formal interview).

\section{$\underline{\text { Transferability }}$}

Not only was the stress reducing approaches used by the children throughout the program and in a variety of other settings, but the children described their ability to teach others these techniques. The instructors recollected on numerous occasions students explaining their successful attempts at "teaching my sister, my mom and my dad how to deep breathe" or "I taught my little brother how to do the positive self-talk. He uses it only sometimes, but he is very small".

The instructors often urged the children to supplement their learning but explaining and teaching their favorite tactics to someone who they thought needed them:

I would give the children some homework sometimes. I would tell them to go teach the deep breathing or the self-talk to someone who they think may need to learn it. The kids would come back all excited and say my mom and dad were arguing and I taught them my deep breathing exercises and it made them feel a lot better. Or, I taught my parents about the self-talk. I told them when they are mad or angry to tell themselves, to calm down and that everything will work out. It seemed like the students taught family members all the time. (Tonya stimulated recall interview).

One commonality found was the desire of students to teach these techniques to their parents. Children repeatedly express their determination to "Teach my parents how to deep breathe, because they always seem stressed and fight a lot". The children believed so adamantly that these 
techniques are effective that they actively attempt to teach family members these stress reducing methods.

\section{Instructors Perceptions of the Program}

\section{Initiating the program}

Prior to the programs inauguration all instructors described feelings of apprehension due to one central reason. The instructors articulated their trepidation teaching the children psychological stress reduction methods due to their inexperience. Although, the teachers underwent a training session with a family counselor with prior experience working with trauma recovery instructors, the teachers were concerned about their ability to successfully implement the psychological strategies into the curriculum.

I do not really have any concerns teaching the physical activity portion. I know we got the training and all, I am just a little worried how all that stress stuff is going to work out. I have not ever taught anything like that before. (Tom formal interview).

I know you explained how the psychological stuff is going to work in there and what you want us to do, but I am not really sure how it is going to work or how successful it will be. (Wendy formal interview).

Teaching physical education was second nature and caused no anxiety for any of the instructors. However, they professed their willingness to participate in the program, even though they were uneasy teaching these stress methods.

\section{Apprehension}

Another reluctance the instructors conveyed was anxiety due to the ties the program had with the tornado, the children who were directly affected by it. Being in this environment induced countless emotions. At the onset, the instructors all wanted to help in any way possible, however they were "a little nervous about it, only because it dealt with the tornado and I do not really like dealing with that stuff". Instructors thought that discussing the storm may bring back unpleasant emotions and feelings causing some uneasiness. When asked why discussing the tornado made them feel this way Becca responded by stating:

I just do not like talking about it. It was a big deal. I mean I have never seen a tornado except for in the wizard of oz. Living in California we have some earthquakes but every few years and coming out here we have tornado warnings left and right and it is just a little different than what I am used to. Talking about the storm and hearing the students talk about it brought me right back to that day, all the emotions everything. (Becca formal interview). 
In the case of these instructors, facing this apprehensions lead to mixed outcomes at the conclusion of the program:

I would definitely do the program again, but if you did it again I would want someone other than me to talk about their tornado story. I do not like to be a part of that, but as far as teaching the different stress reduction methods and skills you know I am all for that 110\%. (Becca stimulated recall interview).

\section{Reasons Instructors Participated in the Program}

The instructors described excitement, guilt and giving back to the community as the focal causes leading to their participation in the recovery program. Although they expressed feelings of anxiety and apprehension before initiating all of the instructors explained feelings of excitement prior to the initiation of the program. All instructors wanted to aid children in recovery and expressed excitement toward being able to commence that process.

\section{Excitement}

All of the instructors expressed their excitement to contribute to the recovery program. They all agreed, "as much as I was nervous to start the program, I was really excited just to be there for the students". Wendy mentioned eagerness to teach as the main reasons for her participation:

I was really excited to do it, in particularly the teaching aspect of it, I am glad you did not ask me to video tape. I just love being around children and helping them learn just about anything. I like any opportunities to teach right now. Either in school or after. (Wendy formal Interview).

One of the main reasons why I was so excited to start the program was, because I knew how much this opportunity could help them out. Not only that, but I knew they would have fun and hopefully learn something along the way. (Tom formal interview).

All of the instructors confirm their strong affinity toward teaching especially any sort of physical activity. The opportunity to be able to assist children affected by the tornado created an intense eagerness among the instructors, which was one of the driving forces behind their involvement.

\section{Guilt}

One of the primary insights one of the instructors gave which led to her contribution to the program was an extreme sense of guilt following the tornado: 
Immediately after the tornado, if I had to describe how I felt, I guess it was not worried or scared I felt guilty. I felt guilty that I only thought about myself during the whole tornado. Until right after it happened and then I saw everybody and knew that everybody was not ok. I think that is really something that you never get over. (Wendy formal interview).

It actually made me feel guilty and selfish and bad about myself. When it was happening, I did not think about anybody other than myself and my boyfriend at the time, and made sure we were safe. It did not even cross my mind that everybody was not ok. Or that people could not be ok that I knew. (Wendy formal interview).

Wendy described an intense feeling of guilt directly after the storm which stuck with her and helped in her decision to teach this program. These feelings of guilt remained with her throughout the duration of the sessions. Wendy described her thoughts during the stimulated recall interview following Tom's story in which he recounting his experience losing his house and possessions.

I had never heard his story before so it was heart wrenching. I knew that he was directly affected and had seen pictures or his house, but I did not know the whole story behind it, I did not know he slept at the REC, anything like that. I felt bad telling my story, because nothing really bad happened to me. At the time I thought it was such a big deal, that I had to go through something like that, you just feel sorry for yourself that you have to deal with it. (Wendy stimulated recall interview).

After you hear other peoples stories I think about what I went through at the moment and what a big deal it was to me but I guess I do not try to think of it. I do not try to think of this experience as something that I went through just because I was so grateful to have. I have everything, I did not lose anything. I guess not being directly affected, but indirectly affected. Being able to teach these children who were affected helped me alleviate some of that guilt. I feel as if I am benefiting them at least somewhat. (Wendy formal interview).

The opportunity to engage with these children who were so clearly in need gave Wendy a sense of relief from the guilt that was immovable since April $27^{\text {th }}$ yet "it is a year later and it makes me feel guilt that I ever felt bad for myself". 
Giving back to the community

Prior to the start of the recovery program, the instructors found a multitude of ways to provide for the community in need. Volunteering ranged from cooking, clearing yards, removing debris, to donating supplies, however "they did not feel like they was really helping out the best way they could". Tom describes the program as "an opportunity for me to give back. I was able to help children recover who really truly needed it". This same sentiment was shared by all the instructors and was described as a major motivation for helping with the program.

Many of the instructors knew that they wanted to assist and were not sure in what capacity they could be the most beneficial. "I knew I could teach physical education, I just was not sure how that would help the kids". When presented with an opportunity to integrate what they were comfortable teaching with the stress reduction methods, the teachers knew the great benefits the program possessed and wanted to help:

I knew how good physical activity can make you feel, and you explained how the stress techniques could help the children feel better. I figured hey, what better way to give back to the community that needed it the most by teaching some sports and that other stuff too. (Becca formal interview).

Having previously volunteered in the rebuilding process the instructors already knew "how it felt to help on my own. I received so many benefits just from helping people". They understood how much of an immediate impact menial tasks had on the community, so when this opportunity arose all instructors jumped on the chance.

When Becca, the instructor most reluctant to do the program due to her concerns reliving the events of April $27^{\text {th }}$, was asked why she agreed to participate being so reluctant she replied:

Yeah, I see the good in it, especially knowing the kids that were in the program. Some do not have homes anymore, some lost family members, most of them lost their school; why not give them an outlet to express their thoughts, feelings concerns. And what better way to do it than through physical activity. (Becca formal interview).

All instructors, even Becca, who was the most hesitant about recalling her harrowing tale, volunteered to assist with the recovery program since they felt it was the most beneficial way to impact the community. Being able to provide the students with much needed support, while concurrently offering the skill they were trained to teach was what enticed these instructors into the program. 


\section{Discussion}

Following natural disasters, children experience a heightened sense of anxiety, anger, aggression and unhappiness. It is important to provide affected children with a positive outlet and environment where they can feel safe (Becker-Blease et al. 2010). Teaching these children how to reduce these symptoms and providing them with a safe, nurturing environment can be immensely essential to their continued success.

Many children recover from normal symptoms with simple family and school support, while other children may continue to experience ongoing symptoms, which can often disrupt their daily functioning. These symptoms can be alleviated if parents and teachers provide emotional support and introduce adaptive coping strategies. The purpose of this study was to evaluate the children and instructors perceptions of their participation within this program aimed to integrate stress-reducing techniques with developmentally appropriate physical activity. There is little surprise that the findings indicated children's enjoyment of the physical activity portion since it is well established that physical activity increases self-confidence, and improves mood considerably (Barrios-Choplin et al. 1997), while having a beneficial effect on reducing anxiety (Biddle and Asare 2011).

The beneficial effects of self-talk on cognitive anxiety were consistent with theoretical assertions that self-talk lies at the core of anxiety (Peale 1956). In children, positive self-talk had been identified as the most frequently reported cognitive coping strategy in stressful situations (Brown et al. 1986). More specifically, the existent evidence base suggests that selftalk has beneficial effects on cognition, cognitive anxiety, and the technical execution of movement skills (Conroy and Metzler 2004). Incorporating self-talk in this environment was perceived by the children as simple to use and were frequently utilized in additional outside environments.

Following previous research establishing that deep breathing is an effective way to decrease acute stress in children (Nogawa et al. 2007), this study successfully implemented deep breathing. These children were trained in its application which led to continued use throughout the program and in other settings as well. Due to the perceived effectiveness of this technique it is vital for parents and physical education teachers to demonstrate this concept with children affected by traumatic events. Explaining the beneficial effects of the self-soothing relaxation techniques can promote the deactivation of the "fight or flight response" in emotionally troubled youth (Perry et al. 1995).

When constructing a natural disaster recovery program with a stress reducing technique component, it is crucial for children to comprehend the specific strategies, and under what circumstances they should be used. These strategies were found to be more effective when the child recognizes that they can initiate these strategies whenever they are emotional, feel stressed, upset or angry. It is imperative for the instructors to articulate this 
importance and provide the children with examples of when they tactics can be used in other environments.

Future research can focus on discovering whether or not the results from this study would transfer following future natural disasters or during other periods of high stress. Studies describing these programs would be extremely beneficial for physical educators, teachers and parents. The results of this study may be generalized to aid following other traumatic events such as wars, earthquakes or other high stress situations. Providing children with the opportunities to learn such stress reducing techniques seems beneficial, and these results may be generalized to other countries as well.

\section{References}

Appleton V (2001) Avenues of hope: art therapy and the resolution of trauma. Art Therapy: Journal of the American Art Therapy Association 18: 6-13.

Baggerly J, Exum HA (2008) Counseling children after natural disasters: guidance for family therapists. American Journal of Family Therapy 36(1): 79-93.

Barrios-Choplin B, McCraty R, Cryer B (1997) An inner quality approach to reducing stress and improving physical and emotional wellbeing at work. Stress Medicine 13: 193-201.

Becker-Blease KA, Turner HA, Finkelhor D (2010) Disasters, victimization, and children's mental health. Child Development 81: 1040-1052.

Biddle SJH, Asare M (2011) Physical activity and mental health in children and adolescents: a review of reviews. British Journal of Sports Medicine 45(11): 886-895.

Brown JM, O'Keeffe J, Sanders SH, Baker B (1986) Developmental changes in children's cognition to stressful and painful situations. Journal of Pediatric Psychology 11(3): 343-357.

Carolan R (2001) Models and paradigms of art therapy research. Art Therapy: Journal of the American Art Therapy Association 18(4): 190-206.

Carson RL (2008) Introducing the lifetime exercise and physical activity servicelearning (le pas) program. Journal of Physical Education, Recreation \& Dance 79(1): 18-22.

Conroy DE, Metzler JN (2004) Patterns of self-talk associated with different forms of competitive anxiety. Journal of Sport \& Exercise Psychology 26: 69-89.

Deaver SP (2002) What constitutes art therapy research? Art Therapy: Journal of the American Art Therapy Association 19(1): 23-27.

Dunn AL, Trivedi MH, O’Neal HA (2001) Physical activity dose-response effects on outcomes of depression and anxiety. Medicine \& Science in Sports \& Exercise 33(6): 587-597.

Eaton LG, Doherty KL, Widrick RM (2007) A review of research and methods used to establish art therapy as an effective treatment method for traumatized children. The Arts in Psychotherapy 34: 256-262.

Flanagan JC (1954) The critical incident technique. Psychological Bulletin 4: 327358.

Goetz JP, LeCompte MD (1984) Ethnography and Qualitative Design in Education Research. Orlando: Academic Press, Inc. 
Han JN, Stegen K, De Valck C, Clement J, Van de Woestijne KP (1996) Influence of breathing therapy on complaints, anxiety and breathing pattern in patients with hyperventilation syndrome and anxiety disorders. Journal of Psychosomatic Research 41(5): 481-493.

Hardy J (2006) Speaking clearly: a critical review of the self-talk literature. Psychology of Sport \& Exercise 7(1): 81-97.

Harper FD, Harper JA, Stills AB (2003) Counseling children in crisis based on Maslow's hierarchy of basic needs. International Journal for the Advancement of Counseling 25(1): 10-25.

La Greca AM, Prinstein MJ (2002) Hurricanes and earthquakes. In AM La Greca, WK Silverman, EM Vernberg, MC Roberts (Ed.), Helping Children Cope with Disasters and Terrorism. Washington, DC: American Psychological Association.

Lehrer PM, Woolfolk RL, Sime WE (2007) Principles and Practice of Stress Management $\left(3^{\text {rd }}\right.$ ed.). New York, NY: Guilford Press.

Lonigan CJ, Phillips BM, Richey JA (2003) Posttraumatic stress disorder in children: Diagnosis, assessment, and associated features. Journal of the Child and Adolescent Psychiatric Clinics of North America 12: 171-194.

Myers D (1994) Psychological recovery from disaster: key concepts for delivery of mental health services. National Center for Post-Traumatic Stress Disorder Clinical Quarterly 4: 1-5.

Nogawa M, Yamakoshi T, Ikarashi A, Tanaka S, Yamakoshi K (2007) Assessment of slow-breathing relaxation technique in acute stressful tasks using a multipurpose non-invasive beat-by-beat cardiovascular monitoring system. ConfProc IEEE Eng Med BiolSoc: 5323-5325.

Patton MQ (1990) Qualitative Evaluation and Research Methods (2 ${ }^{\text {nd }}$ ed.). Newbury Park, CA: Sage Publications.

Peale NV (1956) The Power of Positive Thinking. Greenwich, CT: Fawcett.

Perry B, Pollard R, Blakely T, Baker W, Vigilante D (1995) Childhood trauma, the neurobiological adaptation and "use-dependent" development of the brain: How "states become traits". Infant Mental Health Journal 16(4): 271-291.

Sarid O, Huss E (2010) Trauma and acute stress disorder: a comparison between cognitive behavioral intervention and art therapy. Arts in Psychotherapy 3(7): 8-12.

Shore A (1997) Promoting wisdom: the role of art therapy in geriatric settings. Art Therapy: Journal of the American Art Therapy Association 14(3): 172177.

Slayton SC, D'Archer J, Kaplan F (2010) Outcome studies on the efficacy of art therapy: a review of findings. Art Therapy: Journal of the American Art Therapy Association 27(3): 108-119.

Speier AH (2000) Disaster relief and crisis counseling. Psychosocial Issues for Children and Adolescents in Disasters. Rockville, MD: Center for Mental Health Services.

Stevenson M, Orr K (2013). Art therapy: stimulating non-verbal communication. Nursing \& Residential Care 15(6): 443-445.

Theodorakis Y, Weinberg R, Natsis P, Douma I, Kazakas P (2000) The effects of motivational and instructional self-talk on improving motor performance. The Sport Psychologist 14: 253-271.

Vogel JM, Vernberg EM (1993) Children's psychological responses to disaster. Journal of Clinical Child Psychology 22: 464-484. 
Wahl-Alexander Z, Sinelnikov OA (2013) Using physical activity for an emotional recovery after a natural disaster. Journal of Physical Education, Recreation \& Dance 84(4): 23-28.

Warchal JR, Graham LB (2011) Promoting Positive Adaptation in Adult Survivors of Natural Disasters. Adultspan Journal 10(1): 34-51.

Webb NB (2004) Mass Trauma and Violence. Helping Families and Children Cope. New York: Guilford Press.

Weinberg RS (1988) The Mental Advantage: Developing your Psychological Skills in Tennis. Champaign, IL: Human Kinetics.

Weinberg R, Grove R, Jackson A (1992) Strategies for building self-efficacy in tennis players: a comparative analysis of Australian and American coaches. The Sport Psychologist 6: 3-13.

Wolmer L, Laor N, Dedeoglu C, Siev J, Yazgan Y (2005) Teacher-mediated intervention after disaster: a controlled three-year follow-up of children's functioning. Journal of Child Psychology and Psychiatry 46: 1161-1168. 